\title{
Dos momentos constitucionales en Juan Bautista Alberdi: entre Théodore Jouffroy y Benjamin Constant
}

\author{
Two constitutional moments in Juan Bautista Alberdi: \\ between Théodore Jouffroy and Benjamin Constant \\ MERCEDES BETRIA' \\ GABRIELA RODRÍGUEZ ${ }^{2}$
}

\begin{abstract}
Resumen: Analizamos dos momentos constitucionales en la obra de Juan Bautista Alberdi a partir de sus lecturas de Théodore Jouffroy y Benjamin Constant. En el primer caso, ponemos en relieve la concepción filosófico- moral del derecho así como el modelo de publicista que fue Jouffroy para el "joven" Alberdi de 1837. En el segundo, analizamos el modo en que, en 1852, adoptó la postura de Constant para pensar la autoridad política a partir de las diversas teorizaciones del "poder neutral" plasmado en la figura presidencial de la Constitución Nacional de la República Argentina sancionada en 1853.
\end{abstract}

Palabras claves: derecho; política; filosofía; moral; poder neutral.

Abstract: We analyze two constitutional moments in the work of Juan Bautista Alberdi from his readings of Théodore Jouffroy and Benjamin Constant. In the first case, we emphasize the moral philosophical conception of law as well as the writing model that was Jouffroy as publicist for the "young" Alberdi of 1837. In the second, we analyze the way in which, in 1852, he thought, as Constant did, the political authority from the various theories of "neutral power" that Alberdi embodied in the presidential figure of the Constitution of Argentina adopted in 1853.

Key words: law; politics; philosophy; morality; neutral power.

Cómo citar: Betria, M. \& Rodríguez, G. (20/8). Dos momentos constitucionales en Juan Bautista Alberdi: entre Théodore Jouffroy y Benjamín Constant. Cuadernos Filosóficos, 15. https://doi.org/10.35305/cf2.vil 5.44

Publicado bajo licencia Creative Commons Atribución-SinDerivadas 4.0 Internacional [CC BY-ND 4.0] 


\section{Introducción}

¿Cuál es la distancia que mancomuna el pensamiento de Benjamín Constant con el de Théodore Jouffroy? La Francia de la Restauración cobijó en su seno a escritores y publicistas "viejos" y "nuevos" que supieron que su misión intelectual se inscribía en su propio tiempo contemporáneo y que debían dar al orden político posrevolucionario un gobierno representativo que, con la Charte de 1814 , había adquirido un nombre pero que aún debía convertirse en realidad.

Constant fue, en este sentido, un verdadero referente para los jóvenes que como Jouffroy, participaron de los debates políticos entre 1814 y 1830 , cuando de lo que se trataba era de pensar una república representativa dentro de un orden estable que respetara las tradiciones y símbolos de la nación.

Representante indiscutido del liberalismo francés junto a Francois Guizot, Constant dedicó su escritura a pensar diversos modos institucionales de organizar la autoridad política moderna evitando los excesos de la democracia. Desde su perspectiva, más allá de las múltiples propuestas ofrecidas a los gobernantes a lo largo de su vida, el poder debía distribuirse de tal forma que no apagara las energías de una sociedad de individuos cuyas libertades modernas debían ser la escollera a la nueva forma torrencial del poder popular.

Los trabajos de política y de derecho de Constant son fragmentarios pues se (re) escribían al calor de los debates en torno a la censura o a la libertad de prensa a medida que las decisiones de los gobernantes iban avanzando, o no, en su búsqueda de adecuar las instituciones a la nueva sociedad surgida de la Revolución. Todos ellos, sin embargo, están atravesados por un dilema común: el de pensar el gobierno representativo en una república nueva que, al mismo tiempo, debía conservar la vieja unidad espiritual francesa reencarnada ahora en "el Pueblo".

Miembro de la generación de los globistes, los jóvenes liberales que conformaron el círculo intelectual de Le Globe, Jouffroy fue un discípulo autónomo del eclecticismo de Víctor Cousin y un admirador de los Principios de Política de Constant. Este joven profesor de filosofía fue un verdadero modelo de publicista en el seno de su generación, tanto en Francia como en el Río de la Plata, pues supo comunicar un sentimiento compartido: la necesidad de abrir el espacio público a las "jóvenes capacidades" que fueran los protagonistas de un tiempo de 
ciencia y no de guerra. Como lo había proclamado Jouffroy, era necesario terminar con los viejos dogmas resguardados tras los muros de la Sorbona para construir un nuevo lazo social laico a partir de una filosofía abierta a los ciudadanos.

En el Río de la Plata fue Juan Bautista Alberdi, estudiante de derecho en la Universidad de Buenos Aires, joven ansioso en devenir profesor de filosofía, quien mejor supo traducir el proyecto de Jouffroy. Su libro de filosofía política, el Fragmento Preliminar al estudio del derecho se inscribe en ese dilema constantiano que es la permanencia de lo antiguo en lo moderno y es la expresión consumada de la voluntad jouffroisiana de la filosofía como tarea, teórica y práctica, de las nuevas generaciones.

Lector asiduo y atento a las "novedades inteligentes" provenientes de Francia, Alberdi consagró su vida a pensar la organización política moderna en el Plata legando una vasta obra escrita en donde reencontramos a Jouffroy y Constant, no sólo por el contenido de sus lecturas sino porque estos escritores fueron verdaderos modelos de escritura: le sirvieron para pensar la política y para comprender que ésta debía ser parte de una reflexión colectiva. Así la escritura alberdiana, como la de los franceses, es la puesta en práctica de una concepción de ciencia al servicio de la institución del gobierno representativo moderno.

En su Fragmento..., Alberdi propuso una "ciencia de la política" concebida a partir de un nuevo enfoque filosófico del derecho, según Jouffroy, mientras que en su famoso texto Bases y puntos de partida para la organización política de la República Argentina aplicaría, como lo había hecho Constant, su conocimiento al servicio del Poder/legislador. Ambos textos reflejan dos "momentos constitucionales" que, con notables permanencias, también introducen un cambio pues pasaría de fundamentar, como buen ecléctico, una constitución "en la conciencia del Jefe" del Estado a elaborar un proyecto de constitución escrita donde retomaría, como eje central de ese esquema, al poder neutral constantiano en la figura presidencial.

De este modo nuestra propuesta es analizar la concepción del derecho y el modelo de publicista que fue Jouffroy para Alberdi en 1837 y el modo en que en 1853 adoptó la mirada de Constant para inscribir la autoridad política en una Constitución Nacional. 


\section{MERCEDES BETRIA \& GABRIELA RODRÍGUEZ Dos momentos constitucionales en Juan Bautista Alberdi}

\section{La causa del Fragmento...}

«La cause de ce jeune homme est très belle: je vous assure que je suis charmé de sa lettre et que je répondrai avec plaisir» (Alberdi, 1900, p. 232) ${ }^{3}$. Así le respondía nada menos que Eugène Lerminier a Florencio Balcarce, estudiante en el Colegio Real de París, por cuyo intermedio, Alberdi se presentaba al distinguido profesor, con cartas y trabajos. Como le comunicaba Balcarce:

Obedeciendo a su apreciable del 20 de octubre del año pasado; tuve el placer de entregar al señor Lerminier la carta y demás papeles que Vd. le dirigió. Con este motivo le hice a principios de enero una visita, que he repetido dos veces. El primer día me hizo traducir la carta y tomó de mí las noticias que pude darle sobre vd. y sobre el país. Me preguntó la edad de vd., si era profesor en la Universidad, si estaba mezclado en las revueltas del país, si su carácter era ardiente, etc. (Alberdi, 1900, p. 23I)

Sin dudas, entre esos papeles recibidos por Lerminier, se encontraba el Fragmento preliminar al estudio del derecho cuyo Prefacio era de enero de 1837. La impresión que había generado "la causa" de Alberdi allí delineada debió haber sido muy buena y su contenido considerado lo suficientemente elaborado como para que un escritor consagrado preguntara si Alberdi era profesor en la Universidad. Lerminier no estaba tan errado porque, en efecto, el propósito de Alberdi al escribir el libro había sido comunicarle a su compañeros, en calidad de monitor de estudios ${ }^{4}$, una nueva perspectiva moral del derecho según el eclecticismo de Théodore Jouffroy.

Lo hizo en un libro profundamente romántico en su forma y en su contenido. En su forma, como estructura hojaldrada en tres partes, el Prefacio, el Texto y las Notas, recorridas por una textura abigarrada donde conviven el ensayo filosófico, la propuesta política y el panfleto, verdadera pretensión de mélange decimonónica.

3 "La causa de este joven hombre es hermosa, le aseguro que estoy encantado con su carta y que le responderé pronto", palabras de Eugène Lerminier reproducidas en carta de Florencio Balcarce a Alberdi fechada el 12/3/I838. La traducción en éste y todos los casos es nuestra.

4 Es posible que este texto fuera escrito bajo la supervisión de Diego Alcorta, profesor de filosofía de Alberdi, para colaborar con él en algunos cursos: "Nosotros no somos abogados, no somos jueces, no somos maestros, no somos nada todavía: no estamos, pues, obligados a saberlo todo. Somos aún escueleros [...] Pero tenemos sospechas y las decimos francamente a nuestros colegas, de la debilidad y estrechez de la antigua enseñanza y de la extensión y miras de la futura. Deseamos entablar con ellos un aprendizaje normal, en que comenzamos teniendo el honor de ser monitores" (Alberdi, 1955, p. 86). El subrayado es nuestro. 


\section{MERCEDES BETRIA \& GABRIELA RODRÍGUEZ Dos momentos constitucionales en Juan Bautista Alberdi}

En su contenido, los conceptos provenían de un paradigma epistemológico- político heterogéneo, nacido como parte de una "oposición liberal" a los Borbones y que luego pasaría a consolidarse como "liberalismo de gobierno" (Roldán, 2007, p. 336) con el régimen de Julio. A la manera de los saberes y estilos de Le Globe, el periódico donde convivieron hasta 1830 los eclécticos y los doctrinarios y donde Jouffroy publicó sus manifiestos generacionales ${ }^{5}$, Alberdi quiso hacer de su Fragmento Preliminar su propio manifiesto, "acompañado de una serie numerosa de consideraciones formando una especie de programa de los trabajos futuros de la inteligencia argentina" (Alberdi, 1955). Quería entusiasmar a los jóvenes estudiantes para que se abocaran al estudio científico del derecho, preparando saberes disponibles para el momento en que la política necesitara de su ciencia, $y$, a la manera Jouffroy, convertirse en un verdadero publicista moderno: "Principiemos, pues, por la ciencia. Ella debe estar prevenida para el día en que la política, y no los abogados, competente y exclusiva iniciadora y creadora de los códigos, disponga de ella. Puede importar este aviso a los jóvenes que aspiren a las coronas cívicas" (Alberdi, 1955, p. 96).

Con la publicación del Fragmento preliminar, el joven Alberdi se constituiría en un promotor de la voluntad filosófica, científica, de los estudiantes del Colegio de Ciencias Morales y la Universidad de Buenos Aires que, en 1837 en el Salón Literario iniciaron "el movimiento intelectual" en el Plata. Este gesto suscitaría polémicas y críticas, no sólo debido al conocido apoyo a Juan Manuel de Rosas, el gobernador "tirano" de Buenos Aires sino, fundamentalmente, debido al rechazo cultural que provocaría esa autonomía intelectual de publicar un libro; gesto disruptor profundo de su intencionalidad performativa: la publicidad de la voz joven asumiendo autoría y autoridad para decir el derecho y, por lo tanto, la política.

Esta iniciativa, sin embargo, tuvo seguidores. Manuel José Quiroga Rosa defendería su título de abogado en la Universidad de Buenos Aires en 1837 con un ensayo (Quiroga Rosas, 1956) donde citaba expresamente el libro de su amigo Alberdi ${ }^{6}$; Vicente Fidel López definiría como "alberdistas" (López, 1929, p. 57) a quienes seguían sus ideas y el propio Echeverría lo

5 "De la Sorbonne et des philosophes" (1824) publicado en Le Globe en enero de 1825 y "Comment les dogmes finnisent" (1823) aparecido como suplemento en Le Globe en mayo de 1825. Ambos artículos fueron recopilados en Jouffroy, 1901 .

6 "Ya uno de nuestros mejores escritores ha puesto el primer escudo a las ponzoñosas flechas de esta tendencia mezquina y retrógrada, que asaltaban, no sin suceso, los sentimientos nobles y buenos de nuestra juventud: él nos ha hecho ver el origen de esa antipatía que, es forzoso decirlo, ha manchado la gloria de aquel enorme genio, por haberse constituido con ella, en cierto modo, el antagonista de la humanidad. Yo ayudaría también a nuestro compatriota en su laudable obra, diciendo a nuestra juventud: amemos la filosofía, porque no amándola Napoleón, nos ha dado, sin desearlo, la mas grande lección de filosofía, y por tanto, un ejemplo auténtico de ser filósofos” (Quiroga Rosas, 1956, p. 50). 
caracterizaba como "una facultad analítica sin cotejo entre nosotros" (Echeverría, 1940, p. I 18). Es que Alberdi, como Jouffroy, había sabido expresar un sentimiento compartido por sus colegas de generación a ambos lados del Atlántico: que el siglo XIX los convocaba a organizar un orden político estable mediante un pensamiento colectivo para terminar con los excesos de la revolución.

Así, la polémica pública suscitada con los "viejos", como le llamaban, sería una excusa para legitimar su vocación filosófica en un saber sobre el arte de gobernar, una ciencia de la política, que no residiera en los títulos de los Doctores, ni en la carrera de las armas, sino en los méritos de la capacidad política del publicista: dar inteligibilidad a su época por medio de la escritura de libros doctrinarios. Como recordaría más tarde el propio Alberdi:

$\mathrm{Ni}$ los unitarios, ni los federales, habían formulado la doctrina respectiva de su creencia política en un cuerpo regular de ciencia. Pedid las obras de Varela, de Rivadavia, de Indarte de Alsina y os darán periódicos y discursos sueltos, alguna compilación de documentos, una que otra traducción anotada; pero ni un solo libro que encierre la doctrina, más o menos completa, del gobierno que conviene a la República. No pretendo que no haya habido hombres capaces de formarlos, sino que tales libros no existían. Un tercer partido, representado por hombres jóvenes, inició trabajos de ese orden en 1838, en los cuales están, tal vez, los elementos principales de la organización que ha prevalecido por fin para toda la Nación en 1853. (Alberdi, I886b, p. 487)

Para los jóvenes estudiosos se trataba de organizar el futuro orden político moderno, moderando los excesos y errores políticos de sus mayores a la vez que permitiendo entrar a las esferas de gobierno a las nuevas capacidades a partir de sus méritos.

En cuanto al gobernador de Buenos Aires, había sido la nueva concepción del derecho lo que permitió que Alberdi pudiera analizar el gobierno de Rosas como un "objeto de estudio" caracterizado como un momento reactivo de la historia de la centralización política en el Plata y abierto hacia el futuro, cuando fuese superado por un gobierno racional, un tiempo nuevo donde se erigiría una Republica representativa moderna donde la ciencia y la política estuvieran armonizadas en la constitución de una clase política moderna conformada por las jóvenes capacidades. 


\title{
3. Una nueva perspectiva sobre el derecho
}

Al comienzo de la primera parte de su texto, Alberdi recuerda que dejó de lado la tarea a la que se dedicaba, una exposición de la legislación civil de la Confederación Argentina, porque descubrió, al abrir a Lerminier, que antes debía tener una comprensión distinta del derecho:

\begin{abstract}
Dejé de concebir el derecho como una colección de leyes escritas. Encontré que era nada menos que la ley moral del desarrollo armónico de los seres sociales; la constitución misma de la sociedad, el orden obligatorio en que se desenvuelven las individualidades que la constituyen. Concebí el derecho como un fenómeno vivo que era menester estudiar en la economía orgánica del Estado. De esta manera la ciencia del derecho, como la física, debía volverse experimental, y cobrar así un interés y una animación que no tenía en los textos escritos ni en las doctrinas abstractas. El derecho tomó entonces para mí un atractivo igual al de los fenómenos más picantes de la naturaleza. (Alberdi, 1955, pp. 4I-42)
\end{abstract}

Siguiendo a Théodore Jouffroy, el punto de partida para comprender el derecho era la naturaleza moral del hombre. Precisamente, la primera parte del Fragmento Preliminar se titula "Teoría del derecho natural". Como reconocía: "La teoría del fundamento moral del derecho que acabamos de exponer, no es propiedad nuestra. En este momento se ocupa M. Jouffroy, una de las primeras capacidades metafísicas de este siglo, de la publicación anual de una obra vasta en que se desarrolla esta teoría bajo una forma de la más alta severidad científica" (Alberdi, 1955, Pp. 120-121).

Fundamentalmente, compartía con él dos proposiciones, casi calcadas en su redacción: por un lado que "el fin de un ser es lo que llamamos el bien de este ser" (Jouffroy, 1843, p. 30) y que "cada ser aspirando a su fin, aspira al bien absoluto" (Jouffroy, 1843, p. 50). De allí se desprendía que la naturaleza del hombre es compleja compuesta de tres elementos: el egoísta (nuestro interés bien entendido), el pasional y el racional o moral. Si uno predominaba sobre el resto, siempre el ser humano era partícipe del bien absoluto. Esta concepción moral del hombre se contraponía a los sistemas llamados egoístas y materialistas, tales como el de Helvetius, Hobbes o Bentham que resaltaban sólo un aspecto del hombre, su interés, ignorando con esta reducción esa inevitable participación humana en un orden superior, valor supremo en la filosofía moral de Jouffroy.

Alberdi compartía el dilema de las jóvenes generaciones de la primera mitad del siglo XIX, la necesidad de reconstruir un nuevo orden social que mantuviera las conquistas de la Revolución Francesa sin el escepticismo exacerbado que negaba toda unión espiritual con un orden superior y que era, para ellos, la causa de la "anarquía moral" de los espíritus. La 
solución encontrada sería la de propugnar una nueva moral laica, el poder espiritual que debía encarnarse en los capaces.

La concepción moral del derecho en el Alberdi del Fragmento Preliminar tiene esa finalidad. Sostiene que el derecho es "la regla fundamental de la sociedad humana" y "una necesidad fundamental de la naturaleza humana" (Alberdi, 1955, p. 133), de allí que no hubiera sociedad que, a pesar de sus conflictos y retrocesos, pudiera quedar fuera del derecho. Es que, desde esta perspectiva, la sociedad, como los hombres, participaba del orden absoluto; ella era la condición misma de la vida de los hombres, a la vez que un producto humano -un "maravilloso producto" (Jouffroy, 1843, p. 368). Por lo tanto, las regulaciones sociales artificiales siempre estarían asentadas en un sustrato "natural", espontáneo: los usos y las costumbres de una sociedad sedimentadas por su propio devenir histórico.

Lo que indicaba Alberdi con esta concepción del derecho, que se adecuaba a la realidad política de la Confederación Argentina, es que la sociedad tenía una base moral indestructible y que, por lo tanto, no puede fundamentarse en una convención social, sujeta a modificaciones: "lo que es una convención puede dejar de serlo según la voluntad del hombre" porque "la verdadera ley existe más allá del hombre" (Alberdi, 1955, p. 115). De este modo, toda legitimidad política debía estar en armonía con ese orden superior. Las formas en que esa política se expresara podrían variar con el tiempo y con el espacio, pero nunca salirse de la estela de ese orden.

Su concepción moral del derecho no implicaba, sin embargo, un rechazo de la visión historicista propia del paradigma romántico. En efecto, es el reaseguro de un orden absoluto lo que le permitía decir, sin desesperar, que el progreso se daba por movimientos activos (la época de la Revolución de 1810 y de la experiencia ministerial rivadaviana) y por movimientos reactivos (el orden rosista) que, notemos, Alberdi se esmeraba por diferenciar de lo "retrógrado" como simple vuelta atrás. A largo plazo, siempre primaría la armonía del orden universal que se valía de estos momentos activos y reactivos, para realizar su finalidad.

Precisamente, después de dedicarle varios capítulos a esta concepción moral del derecho, Alberdi remataba sus consideraciones con una "contraprueba histórica de las verdades precedentes" (Alberdi, 1955, p. 135) donde enunciaba su doctrina de las edades de los pueblos que primero piden el derecho instintivamente hasta llegar, por etapas, al reino de la razón. Desde esta perspectiva el Río de la Plata no distaba mucho del "reinado de la voluntad" etapa orgánicamete anterior a la de la razón (Alberdi, 1955, p. 136). 


\section{MERCEDES BETRIA \& GABRIELA RODRÍGUEZ \\ Dos momentos constitucionales en Juan Bautista Alberdi}

\section{El rol del publicista}

La interpretación de la revolución de Julio como una revolución regeneradora de la sociedad moderna a partir del poder constructivo de las ideas, permitió que los jóvenes del 37 se experimentaran a sí mismos como emergentes legítimos de la sociedad moderna en el Plata, en tanto iniciadores de un "movimiento intelectual" (Echeverría, 1940, p. 75) fundador de una nueva temporalidad: el siglo XIX, no sólo espacio de experiencia cronológico, sino espacio de experiencia de un tiempo nuevo y moderno que sólo podía ser creado en un trabajo de institución de lo social como labor intelectual, colectiva y generacional. Éste había sido el sentido que Jouffroy le había dado a la empresa generacional que debía impartirse desde Le Globe en sus famosos artículos-manifiestos Comment les dogmes finissent (1823) y De la Sorbonne et des philosophes (1824), que darían una de las pautas centrales de los jóvenes liberales europeos y rioplatenses: la misión de "construir" un siglo moderno. Como recuerda Vicente Fidel López el libro de Jouffroy le había causado un gran impacto:

Querido amigo, me place hacerle llegar el libro Las Misceláneas filosóficas de Mr. Jouffroy. De cuantas maravillas, señor Félix, se ha regalado mi alma gracias a la lectura de este libro bello. Ha sido necesario que pasaran varios días antes que pudiera despertar del sueño en el que me sumergió. He realizado varios extractos que servirán para explicar y profundizar las otras doctrinas del autor en su obra Curso de derecho natural, que ya tenemos?. ("Carta a Félix Frías", Buenos Aires, 1838. En Vermeren, 1997, p. 5)

Dichos artículos fueron verdaderas guías de la empresa intelectual de la generación francesa de 1820 y de la argentina de 1837 porque allí, el discípulo de Víctor Cousin había logrado formular una tarea histórica para las jóvenes generaciones: la posibilidad de terminar la revolución material violenta del siglo XVIII con una revolución pacífica de las ideas en el siglo XIX.

Lo que tuvo un valor performativo fue el propio Jouffroy quien, en tanto escritor y profesor, había legitimado públicamente en la prensa la aspiración de los publicistas modelo siglo $X I X$ al manifestar que todas las generaciones tenían una tarea específica en el movimiento de la historia y en la renovación de los dogmas, y que había llegado la hora de la nueva generación, destinada a ser la autora de una nueva moral filosófica laica para conducir la

7 "Cher ami, il me plaît de vous faire parvenir le libre Les Mélanges philosophiques de Mr. Jouffroy. De quelles merveilles, Sr. Félix, mon âme s'est régalée, grâce à la lecture de ce beau libre. II a fallu qu'il se passe plusieurs jours pour que je me réveille du rêve dans lequel celle- ci m'avait plongé. J'en ai fait aussi plusieurs extraits qui servent à expliquer et approfondir d'autres doctrines de l'auteur dans son oeuvre, Cours de droit naturel que nous possédons". Esta fuente fue publicada por primera vez por Vermeren en francés. 
revolución en las ideas. En el caso de la Generación del 37 esta moral laica se resumió en las 15 Palabras Simbólicas del Código o declaración de principios que constituyen la creencia social de la República Argentina, texto redactado por Echeverria pero discutido en el seno de la Asociación de la Joven Generación Argentina, en 1838 y publicado por primera vez en EI Iniciador de Montevideo en enero de 1839.

Alberdi expresaría en varias ocasiones su admiración por Jouffroy a quien consideraba "un hombre de nuestra época" (Alberdi, 1838, p. 2), el "filósofo más contemporáneo" (Alberdi, I886b, p. 604) porque lo que hacía Jouffroy con la filosofía era expresar el tiempo y el lugar del publicista. En efecto, como indicaba Jouffroy en De la Sorbonne et des philosophes el paso del siglo XVIII al XIX era el de la conversión del sabio de la Sorbona cuyo conocimiento quedaba oculto en una "oscuridad majestuosa" (Jouffroy, 190I, p. 20) a la conformación del escritor público que en salones "discutía y pronunciaba oralmente" su opinión sobre ideas; era la transformación del doctor en publicista, que no era ni el sabio ni el Filósofo de la llustración, pero que hacía filosofía de cara al pueblo, a la opinión pública.

En el Fragmento Preliminar Alberdi había propuesto como "manual" de la juventud la Lección $\mathrm{N}^{\circ} 10$ del Curso de derecho natural de Jouffroy, denominada "Del escepticismo actual”: "M. Th. Jouffroy ha consagrado la lección duodécima ${ }^{8}$ de su Curso de Derecho Natural a la exposición de una teoría luminosa de las revoluciones y una ojeada profunda de la situación actual de la gran revolución de la civilización humana. Este fragmento debiera ser el manual de nuestra juventud. Es un antídoto contra la manía de revolver" (Alberdi, 1955 p. 66).

Alberdi citaba parte de esa lección para justificar su propia decisión de escribir y publicar el Fragmento Preliminar, un texto clave para la formación de la sociabilidad generacional. Alberdi se preguntaba:

¿Porqué hemos entrado nosotros en estas últimas consideraciones?" y respondía
porque "todo hombre que comprende bien su época, tiene una misión patriótica que
llenar, y consiste en hacerla comprender por los demás; en calmar así el país como se
ha calmado a sí mismo. Desde que se comprenden bien las circunstancias del estado
en que nos encontramos, deja uno de asustarse; cuando uno cesa de asustarse, piensa
en sí mismo, se forma un plan de conducta, se trabaja, se vive. (Alberdi, 1955 p. 79)

En esta lección Jouffroy retomaba su análisis, más breve, de Comment les dogmes finissent, donde relataba el movimiento de la historia en tanto pasaje del viejo orden a uno nuevo a

8 Es éste un error de Alberdi, dado que, en rigor, se trata de la lección $N^{\circ} 10$.

9 Son las mismas palabras de Jouffroy, 1843, p. 323. 
partir de la "revolución de las ideas" (Jouffroy, 190I, p. 7), es decir, el modo en que el "dogma viejo" que sostenía un poder y una dominación en el "viejo régimen" era combatido por "el espíritu de examen" de una generación que venía a cuestionar ese dogma; de esta manera, decía Jouffroy, los hombres nuevos lograban que el pueblo, que obedecía por "rutina indiferente" (Jouffroy, 1901, p. 2), saliera de su "apatía" (Jouffroy, 190I, p. 3) y de su “costumbre y veneración por el pasado”(Jouffroy, 190I, p. 4). Ese espíritu de examen era la filosofía, una "fuerza moral" que se ponía en lucha con la "fuerza material". Pero, en una primera etapa de este desarrollo, la filosofía era la de la duda, la del escepticismo, de allí que fuera necesaria una "generación nueva" que, heredera de estos hombres que combatieron al viejo orden, pudiera construir una nueva creencia que reemplazara los viejos dogmas. Era el pasaje de la generación que había derrumbado el viejo dogma, a otra que debía construir una "fe nueva", comprometida con su presente y con su época. Este compromiso había marcado también la reflexión constantiana sobre las soluciones políticas propuestas para organizar el poder en las sociedades modernas.

\section{Versiones del poder neutral}

En la trayectoria de Benjamín Constant como pensador político hay tres momentos en los que recurre o conceptualiza la noción de poder neutral. El primero data de 1797 en un texto publicado casi doscientos años después de su producción, Fragments d'un ouvrage abandonné sur la possibilité d'une constitution republicaine dans un grand pays (199I) escrito entre 1896

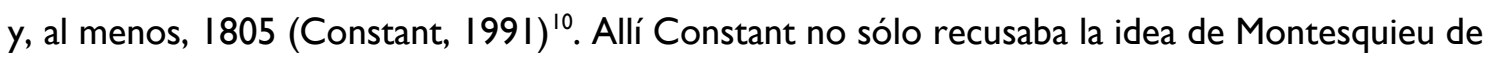
que las repúblicas sólo son posibles en países pequeños, sino que proponía una ingeniería institucional que combinara un poder legislativo bicameral, un poder ejecutivo colegiado, una judicatura independiente y un poder neutral, también electo por el pueblo pero de manera indirecta, con el fin de que interviniera frente a los potenciales conflictos del resto de los poderes.

Si Constant, como muchos de los patriotas rioplatenses entre 1810 y 1815 , temía a los ejecutivos unipersonales, rechazando así el modelo estadounidense de república, no dudaba en adaptar un instrumento propio de la legitimidad tradicional para conseguir un orden político

10 Este trabajo fue escrito en diálogo no sólo con los textos constitucionales del 13 de diciembre de 1799 (La Constitución de la república francesa dictada por los dos consejos de las asambleas legislativas y los cónsules), el senado consulto del 4 de agosto 1802 (16 Termidor año 10) y el senado consulto 18 de mayo 1804 (28 Floreal del año 12) sino también con los libros de Jacques Necker de 1892, Du pouvoir exécutif dans les grands États, y de Emmanuel Sieyès, Discours du 2 Thermidor de l'An III. 
posrevolucionario estable. Aunque esta formulación del poder neutral no pudo ser conocida por Alberdi, tiene una doble singularidad que merece ser destacada. Por un lado, demuestra que el poder neutral no es incompatible con un régimen político republicano y, por el otro, las atribuciones que se otorgaban al poder neutral en esta versión -como disolver las asambleas y remover al ejecutivo, presidir la administración pública, conmutar penas u otorgar gracia, y representar la continuidad del Estado-, permanecerían inalteradas en sus reformulaciones posteriores.

Así, en Réflexions sur les constitutions (mayo de 1814) (Constant, 1814), Constant readapta las prerrogativas antes descriptas a un nuevo contexto: la monarquía borbónica restaurada pero limitada por una constitución que reconocía derechos y garantías individuales. En los artículos 13, 14, 50, 52 de la "Charte Constitutionnelle du 4 Juin 1814" (Rosanvallon, 1994, p. 250) se enunciaban las atribuciones del poder neutral, ahora encarnado en el rey, y se le agregaba el poder de veto que antes estaba en manos del ejecutivo.

Constant negaría, en tanto opositor de la Restauración, su vínculo con este texto constitucional, sin embargo, la Charte consagraba el principio de legitimidad del liberalismo constitucional: el rey reina pero no gobierna; elemento compartido por el autor en su afán por evitar el despotismo.

A Benjamin Constant le resultaría más difícil ocultar su participación en el proceso de elaboración de L'Acte Additionnel aux Constitutions de l'Empire (1815). Por un lado, su participación queda testimoniada por el relato autobiográfico que él mismo haría de esa experiencia"; por el otro, dedicaría importantes secciones de Principes de Politique (1815) a comentar los artículos de la constitución napoleónica que se hizo célebre con el nombre de benjamine.

Constant no negaría del todo su paternidad respecto de esta constitución que consagraba de un modo bastante acabado el rol y la singularidad del poder neutral: "La monarquía constitucional crea este poder neutro en la persona del jefe de estado. El verdadero interés de este jefe no es que uno de los poderes se sobreponga al otro sino que todos se apoyen, se entiendan y actúen juntos" (Constant, 1997, p. 324) 12

II «Mémoires sur les Cent Jours» en Constant, 1993.

12 “'La monarchie constitutionelle crée ce pouvoir neutre dans la personne du chef d'État. L'intérét véritable de ce chef n'est aucunement que l'un des pouvoirs renverse l'autre, mais que tous s'appuient s'entendent et agissent de concert". 
Esta versión del poder neutral contenía las siguientes prerrogativas: disolver las asambleas, remover el ejecutivo sin recurrir a ningunas de las causalidades habitualmente imputables como responsabilidad parlamentaria de los ministros y el derecho de gracia incluso para los ministros condenados por la cámara de pares. A su vez, aunque esta última cámara era hereditaria, como su número no estaba prefijado, el poder neutral podía crear nuevos pares; además, nombraba a los jueces, pero no podía removerlos. Asimismo el poder neutral tenía poder de veto ${ }^{13}$. Como titular de la Jefatura del Estado, el pouvoir neutre declaraba la guerra y la paz. Constant afirmaba que, en la Benjamine, el poder neutral, al que elude denominar específicamente como "emperador", tenía una autoridad inviolable frente a los ministros que eran políticamente, no sólo penalmente, responsables y, por ende, existía una clara separación entre el poder real y el ministerial (Constant, 1997, pp. 329, 330, 40I, 410, 4I I).

Así pues, los poderes activos se controlaban entre sí; el poder pasivo, el judicial, protegía a los individuos y el poder intermediario intervenía en caso de necesidad para destrabar conflictos institucionales o para restituir la legitimidad.

El pouvoir neutre "es un ser aparte, por encima de la diversidad de opiniones, con el único interés de mantener el orden y la libertad" (Constant, 1997, p. 327) ${ }^{14}$; su reposo, su imparcialidad y su inviolabilidad permitían que, en caso de peligro y necesidad, pudiera, dentro de los medios legales y constitucionales, sosegar los conflictos cuya existencia es necesaria para que exista la libertad. Cuando el poder neutral se encarna en una figura personal se hace más evidente esa función de intermediario que, por momentos, se confunde con pasividad, si por actividad se entiende el gobierno de lo cotidiano y no el ejercicio de la autoridad representativa casi en estado puro.

\section{De la Benjamine al proyecto de Constitución argentina de 1853}

"Se atribuye a Bolívar este dicho profundo y espiritual 'Los nuevos Estados de la América antes española necesitan reyes con el nombre de presidentes”' (Alberdi, 19l4, p. 4I). La mayoría de los estudiosos del poder neutral en las constituciones latinoamericanas del siglo XIX rechazan la posibilidad de encontrar esta figura más que en la constitución brasileña de

13 Aunque es ambigua su determinación sobre si se trata de un veto total o parcial.

$14 \mathrm{El}$ poder neutro «est un être à part, supérieur aux diversités des opinions, n'ayant autre intérêt que le maintien de l'ordre et le maintien de la liberté». 


\section{MERCEDES BETRIA \& GABRIELA RODRÍGUEZ Dos momentos constitucionales en Juan Bautista Alberdi}

1824 donde ese poder es desempeñado por un emperador ${ }^{15}$. No compartimos ese punto de vista: hay diseños institucionales y contextos políticos donde el presidente puede desempeñar ese rol, como ocurre en el proyecto constitucional de Juan Bautista Alberdi.

Tensionado política y conceptualmente entre una república que no se termina de consolidar y tentado por la monarquía como forma posible para ordenar el caos sudamericano, Alberdi se sirve de un poder neutral que conocía sólo en su formulación monárquica. Sin embargo, esta recepción no fue pasiva porque tendría que adaptar la figura a las necesidades de su tiempo. $\mathrm{Si}$ se establece un hilo conductor entre Bases y puntos de partida para la organización política de la República Argentina (1852), La monarquía como mejor forma del gobierno en Sudamérica (1864) $)^{16}$ y La república consolidada en 1880 con la Ciudad de Buenos Aires como capital (188I) hay elementos para pensar al presidente como una especie de pouvoir neutre. Pero se obtiene algo más de precisión al respecto si nos detenemos en su proyecto de Constitución que presenta interesantes variantes respecto de la Constitución de 1853, especialmente en lo relativo a un problema esencial para Alberdi: la composición del poder ejecutivo del que dependía, según sus propias palabras, el futuro de América del Sur.

Tanto en la Constitución Argentina sancionada en $1853^{17}$ como en el proyecto de Alberdi, el presidente es el titular del poder ejecutivo electivo y su cargo es incompatible con la función parlamentaria. El presidente es jefe de Estado, tiene el derecho de indulto o gracia, nombra a los magistrados, aunque comparte el ius belli con el congreso, es el comandante en jefe de las Fuerzas Armadas de la nación y jefe de la administración. En estos puntos, no hay mayores divergencias entre la Constitución de 1853 y el proyecto de Alberdi salvo que el jurista aclara, quizás teniendo en mente un posible conflicto con Buenos Aires, que el presidente es el jefe inmediato y local de la ciudad federal de su residencia (art. 85 inc.3). La diferencia central entre la Constitución sancionada y el proyecto alberdiano está en los alcances, sustantivos, procedimentales $y$ temporales, de la responsabilidad presidencial.

I5 Para una síntesis de estas posturas, cf. Eissa Barroso, 2004. Negretto tiene una postura algo diferente y menciona como ejemplo de recepción del poder neutral constaniano la Constitución chilena de 1823 redactada por Juan Egaña, e incluso afirma que Alberdi pudo conocer esta figura institucional a través de este caso. Aunque desde su punto de vista en la Constitución de 1853 se descartó ese modelo por el estadounidense, concluye que para Alberdi el presidente debía cumplir el rol de instancia neutralizadora del conflicto faccioso. Cf. Negretto, 200I, p. 30.

16 Se trata de un escrito póstumo de Alberdi, pero esa sería la fecha de su elaboración.

17 Esta constitución fue reformada parcialmente en 1860, 1866, 1898, 1957 y 1972 . Su última reforma más abarcativa data de 1994 y es el texto actualmente vigente. Nunca se alteró la estructura del Ejecutivo, aunque en la última modificación se creó la figura del jefe de Gabinete, quien ejerce por delegación del Presidente la administración general del país. 
En los artículos 4I, 47 y 48 de la Constitución de 1853 se establece que el presidente, el vicepresidente y los ministros del poder ejecutivo pueden ser acusados por la Cámara de Diputados y juzgados por el Senado por su responsabilidad. La única diferencia entre el presidente, su suplente y su gabinete responsable es que en caso en que el jefe de Estado sea sometido a juicio político, quien preside el Senado es el titular de la Corte Suprema. La constitución argentina opta aquí por un sistema de responsabilidad a la estadounidense pero, Alberdi, aunque comienza el art.86 de su proyecto diciendo que el presidente es responsable, elige otro procedimiento. Sólo al final de su mandato el Presidente podía ser acusado por aquellos actos de gobierno que hubieran sido contrarios a la Constitución, tanto en sus aspectos formales como materiales:

El presidente es responsable y puede ser acusado en el año siguiente al período de su mandato por todos los actos de su gobierno en que haya infringido intencionalmente la constitución o comprometido el progreso del país, retardando el aumento de la población, omitiendo la construcción de vías, embarazando la libertad de comercio o exponiendo la tranquilidad del Estado. La ley regla el procedimiento de estos juicios. (Alberdi, 1914, p. 167)

Fiel a sus principios políticos, Alberdi adelantaba las causales del juicio político presidencial: haber incumplido con los mandatos sustantivos que el proyecto político-económico triunfante en Caseros le exigía. Pero, no solamente allí radicaba la diferencia con el texto constitucional sancionado en 1853. Para los constituyentes no sólo no era necesario hacer explícita la razón material de la constitución, sino tampoco coincidían en que el Jefe de Estado tuviese que contar con un sistema de juzgamiento diferente del vicepresidente. En ambos casos, se trata de un juicio político donde la Cámara de Diputados es la acusadora y la Cámara de Senadores opera como Tribunal presidido por el Presidente de la Corte Suprema de la Nación cuando el acusado es el titular del Poder Ejecutivo. Su fallo se limita a la destitución pero la parte condenada puede ser "sujeta a acusación, juicio y castigo conforme a las leyes por parte de los tribunales ordinarios" (art. 48 CNA 1853). En el caso del proyecto de Alberdi ese juzgamiento a la autoridad presidencial sólo se permitía una vez cumplimentado su mandato, del mismo modo que se hacía con los virreyes.

Así pues, entre el proyecto constitucional de Alberdi y la Constitución Argentina de 1853 hay una diferencia importante respecto del sistema de responsabilidad presidencial que no ha sido lo suficientemente atendida. Esta diferencia contempla dos aspectos: uno sustantivo o material y otro procedimental que, en realidad, remite a una cuestión de tiempo y circunstancia. En el esquema alberdiano es función del presidente garantizar los principios 
sustantivos de la constitución que no son otros que los valores enunciados explícitamente en Las Bases...: desarrollo económico y social fundamentado en la inversión extranjera y la transmutación poblacional (fomento de la inmigración del norte europeo). Pero para lograr ese ideal de la sociedad civil autorregulada había que contar con un poder cuya autoridad estuviera exenta, al menos temporalmente, del cuestionamiento de otros poderes, directos o indirectos. Se presentaba así una interesante paradoja: los valores del liberalismo estaban protegidos por un poder fuerte y conservador.

\section{Una República presidencial con poder neutral}

Constant plantea en De la responsabilité de Ministres de 1815 que la responsabilidad ministerial se corresponde con los actos ilegales que los ministros cometan durante la gestión política (por ejemplo, detener ilegalmente a una persona) pero no aquellos que puedan cometer en tanto individuos privados (por ejemplo, matar a una amante en un rapto de pasión) cuyo juzgamiento pertenecía a la esfera de la justicia ordinaria. Es por la existencia de esa responsabilidad que el poder neutral puede intervenir en los conflictos haciendo de su reposo una "actividad" restauradora de la calma y facilitando, al remover los obstáculos, que los poderes "ordinarios" vuelvan a actuar. Así pues, el poder neutro es "irresponsable" o es responsable de un modo diferente a sus ministros que son los que desempeñan el Poder Ejecutivo en Francia.

En un modelo institucional donde el Presidente es titular del Poder Ejecutivo resulta difícil separarlo de los vaivenes de la política; pero, si se aspira a que opere como poder moderador, un mecanismo importante es la imputación de responsabilidad. Para Alberdi, la responsabilidad del Presidente no es exactamente homologable con la de los ministros que deben rendir cuentas ante el Congreso. Los motivos de su juzgamiento radican no sólo en la posible ilegalidad de sus actos, sino en el no cumplimiento de los valores que, según el jurista tucumano, se derivaban del pacto político que había dado lugar a la Constitución de 1853. Pero, es de notar que establece que su enjuiciamiento se realice una vez terminada su gestión, cuando volvía a ser un hombre común. De este modo, mientras el Presidente estaba en el ejercicio de sus funciones, se limitaba claramente la responsabilidad política directa de la autoridad presidencial pero no se cuestiona su vínculo con la soberanía electoral, aunque sea limitada, del pueblo. 
La solución alberdiana tenía una clara impronta constantiana pero también una cuota de originalidad, ya que confiaba en la posibilidad de encontrar en el Presidente una figura institucional que, aún siendo juez y parte, lograra institucionalizar el poder personal y estabilizar el sistema político. Para Alberdi era posible negociar una especie de tregua relativa entre el poder personal, que es potencia, generalmente, destructora y la institucionalidad republicana que quiere consolidarse. No obstante, para hacerlo no había que confiar en hombres providenciales sino en el "carisma" de un cargo que transformara al hombre.

Pese a las diferencias entre su propuesta original y el texto constitucional sancionado, Alberdi seguiría interpretando a la figura del Presidente argentino en la misma clave. El problema más importante que tenía que resolver la figura presidencial era la estabilización de una república frente a la lucha facciosa, herencia del caudillaje de las guerras civiles, primero, $y$, más tarde, producto del rol distorsivo de la provincia- metrópoli (Buenos Aires) que se resistía a participar de la unidad-federativa como entidad subordinada a la autoridad nacional: "La soberanía del pueblo argentino, compuesto por todas las provincias unidas en un solo cuerpo, quedó existiendo nominalmente, mientras la máquina o fábrica del poder real, quedó intacta como lo estaba bajo el gobierno de España y de su Virrey de Buenos Aires" (Terán, 1996, p. $287)^{18}$.

En 1852, Alberdi estaba convencido que Justo José de Urquiza no era el déspota oriental que veía en él Sarmiento; quiso hacer del gobernador de Entre Ríos, como Benjamín Constant lo había intentado con Napoleón, un hombre, si no nuevo, diferente a lo que había sido hasta entonces. Alberdi creyó posible transformarlo haciendo que su poder personal instituyente se sometiera, voluntariamente, a ser "parcialmente" instituido. Pero, si Alberdi, fiel a su declarado "conservadurismo", iba a mantener esta línea argumentativa respecto de la necesidad de encontrar la encarnación de un poder que representara la unidad de la nación para que ésta dejara de ser una república tumultuosa, iba a desconfiar, sin embargo, cada vez más de los hombres. Y esa desconfianza alcanzaría, incluso, al hombre con poder real al que había pensado como ejecutor de su sueño constitucional, Urquiza, quien en los últimos textos del jurista tucumano sería descripto como un caudillo tradicional. $Y$, aunque el presidente Julio Argentino Roca (1880-1886) al federalizar la ciudad de Buenos Aires renovase en algo su esperanza en el futuro la República Argentina, Alberdi depositaría su confianza, no en la persona, sino en la institución presidencial por él creada para que hiciera de hombres

I8 El texto reproducido por Terán es "La república consolidada con Buenos Aires por capital" 
comunes, si no grandes hombres, al menos sí, estabilizadores, constitucionalmente limitados, del orden político.

\section{Conclusión}

El Fragmento preliminar... es, tal vez, uno de los primeros textos en declarar una pretensión científica en el abordaje del estudio de la política en el Río de la Plata. A la manera de Théodore Jouffroy, en sus páginas Alberdi presentó la necesidad de alcanzar un estudio filosófico del derecho, ya no como una colección de leyes pertenecientes a un corpus colonial heredado sino en tanto elemento de la vida orgánica del Estado. Al hacerlo, Alberdi plasmaba una convicción compartida por su generación: la necesidad de pensar la política como una materia apta para el conocimiento filosófico y empírico. Por supuesto, ello no implicaba el nacimiento de un campo disciplinar específico, pero si algo vuelve interesante y nos hace releer este texto "fundacional" de nuestra historia intelectual, es precisamente que allí aparecen, en su dimensión performativa y textual, los saberes que debían contribuir a realizar una ciencia de la política, esto es, una ciencia para pensar la política: la teoría del derecho natural según Jouffroy era la más importante, combinada con una lectura de la "soberanía de la razón" compartida por Jouffroy, Constant, y elaborada por Guizot.

Juan Manuel de Rosas se volvió así, un "objeto de estudio" de esta empresa intelectual y, por este rodeo, el punto de partida, más tarde rechazado, para pensar un gobierno representativo en el Río de la Plata. Es que, en efecto, la decisión de Alberdi de exiliarse a Montevideo en noviembre de 1838 implicaría un cambio de estrategia pero, en última instancia, con vistas al mismo objetivo pues, sin Rosas y contra Rosas, el gobierno representativo sería buscado a través de la conformación de una oposición política moderna.

Si en Francia el gobierno representativo se pensó a partir de un liberalismo que desde la oposición llegó al poder, en el Rio de la Plata, los liberales que pretendían pensar en la "silla del poder" (Echeverría, 1940, p. 269) se convirtieron en el destierro en publicistas sin Estado. Este dilema está presente en la estructura híbrida del Fragmento Preliminar.

En efecto, el análisis del Fragmento Preliminar teniendo en cuenta los tres bloques textuales relacionados, pero autónomos al mismo tiempo, da cuenta del carácter performativo del libro: el modo en que Alberdi elaboró sus ideas en relación al contexto local para pensar el orden político en la Confederación Argentina. Así es en el Prefacio donde aparece su polémica con el constitucionalismo unitario y su defensa del momento "reactivo" rosista; en el cuerpo del 
texto, donde ensaya una teoría del derecho en relación a su concepción capacitaria de la política y, finalmente, en las Notas donde avanza en nuevas consideraciones filosóficas, a veces contradictorias, respecto al proceso abierto en 1830, "la revolución en las ideas" protagonizadas por el eclecticismo y el doctrinarismo que nutren estas páginas.

El Fragmento Preliminar tiene la estructura hojaldrada de la que hablaba Lévi- Strauss al analizar la estructura del mito, tal vez, porque allí Alberdi, joven y ansioso lector de las novedades filosóficas en revistas como Le Globe, quiso inscribirse como publicista apto para escribir libros "dogmáticos”.

Aunque ya desde el título de este artículo se hace referencia a la lectura alberdiana de Jouffroy y Constant, nuestro abordaje no está orientado, sin embargo, por la Teoría de la Recepción ${ }^{19}$. Se trata de pensar la relación entre la innovación conceptual e institucional en estos pensadores que desafiaron, por su compromiso con su contemporaneidad, los límites de las tradiciones liberales y republicanas, a las que nunca pretendieron dejar de pertenecer. Respecto de Constant, a diferencia de Jouffroy, la recepción que hace Alberdi es apócrifa, porque rara vez reconoce su fuente, pero al mismo tiempo es original pues adapta el concepto de poder neutral a la forma de organización política republicana que proclamó la Argentina desde inicios del siglo XIX.

Sin embargo, esta lectura se realiza en un contexto específico de la historia del Río de la Plata que no puede desligarse del modo en que fue leído el lausannois entre 1815 y 1830 . Por ello, el momento Constant que busca institucionalizar el orden político sin renunciar a los valores de la Revolución de Mayo de 1810, hermana dos Generaciones: la rivadaviana y la de 1837, generalmente, separadas por el rechazo de la Joven Generación a las ideas y prácticas políticas "utilitaristas" de sus antecesores.

Constant y Alberdi personifican el desafío del republicanismo liberal de combinar un poder fuerte, que estabiliza el orden político, con los principios liberales anti despóticos. Para ambos este dilema es mucho más acuciante que otros liberales decimonónicos, como los federalistas estadounidenses porque la república, lejos de ser una opción política verdadera, o, cuanto menos, posible, se muestra elusiva tanto en Francia como en el Río de la Plata. Es en este marco que resulta mucho más comprensible la apuesta político conceptual de ambos por el poder neutral de raigambre monárquica.

19 Cf. Jauss, 1990. Igualmente, la terminología "horizontes de sentido" y "expectativas" tomada de la filosofía de Gadamer que empleamos en este artículo, participa de la empresa heurística de la teoría de la recepción de Jauss. 
El viaje de Benjamín Constant al fin del mundo no fue en vano. Su recuerdo quedó impregnado en quienes lo leyeron en la primera mitad del siglo XIX y se propusieron construir a través de él los cimientos del orden político poscolonial.

Así, pues, el eco de Jouffroy con su nueva teoría moral del derecho y el de Constant y su poder neutro, permite resignificar la ruptura que implicó conceptual y políticamente la Generación de 1837, de la que Alberdi fue uno de sus principales exponentes, y cuyos aportes aún resuenan en la forma "representativa, republicana y federal" declarada por los constituyentes en 1853.

\section{Referencias}

Alberdi, J. B. (1838). Espíritus positivos. Continuación. La Moda, 22. 14/04//838.

Alberdi, J. B. (1886a). Escritos Póstumos (Vol. II). Imprenta Alberdi.

Alberdi, J. B. (1886b). Obras Completas (Vol. I). Imprenta de la Tribuna Nacional.

Alberdi, J. B. (1955). Fragmento preliminar al estudio del derecho. Hachette.

Alberdi, J. B. (1900). Escritos Póstumos (Vol. XV). Imprenta Alberdi.

Alberdi, J. B. (19/4). Bases y puntos de partida para la organización política de la República Argentina y Proyecto de Constitución. La Cultura Argentina.

Botana, N. (1997). La Tradición Republicana. Sudamericana.

Constant, B. (1991) Fragments d'un ouvrage abandonné sur la possibilité d'une constitution republicaine dans un grand pays. Aubier.

Constant, B. (18|4). Réflexions sur les constitutions, la distribution des pouvoirs, et les garanties, dans une monarchie constitutionnelle. H Nicole à la Librairie Stéréotype.

Constant, B. (1993). «Mémoires sur les Cent Jours». En Oeuvres complètes (Serie I, Vol. 14). Niemayer.

Constant, B. (1997). Écrits politiques: L'esprit de conquête et de l'usurpation, Principes de Politique. Gallimard.

Constant, B. (1815) De la Responsabilité de Ministres. A. Belin.

Echeverria, E. (1940) Dogma socialista. Universidad Nacional de La Plata.

Eissa Barroso, F. A., (2004). El poder moderador en América Latina: el fracaso de una alternativa de diseño institucional. Tesis de Licenciatura, Centro de Investigación y Docencia Económica (CIDE), México.

Goblot, J. J. (1995). La jeune France libérale. Le Globe et son groupe littéraire 1824- 1830. Plon. 
Goldman, N.(dir.) (1998), Nueva Historia Argentina, Revolución, República, Confederación (1806-1852), Tomo III. Sudamericana.

Jauss, H. R. (1990). Pour une esthétique de la réception. Gallimard.

Jouffroy, T. (1843). Cours de droit naturel. Hachette.

Jouffroy, T. (1901). Mélanges philosophiques. Hachette.

López, V. F. (1929) Evocaciones Históricas. El Ateneo.

Negretto, G. (200I). La genealogía del Republicanismo Liberal en América Latina. Alberdi y la Constitución Argentina de 1853. Latin American Studies Association 6(8), PP. I-39.

Palti, E. (2009). El momento romántico. Nación, historia y lenguajes políticos en la Argentina del siglo XIX. EUDEBA.

Quiroga Rosas, M. J. (1956). Sobre la naturaleza filosófica del derecho. Perrot.

Roldán, D. (2007). Guizot. El gobierno representativo. Deus Mortalis. Cuadernos de Filosofía Política, 6, pp. 329-350.

Rosanvallon, P. (2003). Le moment Guizot. Gallimard.

Vermeren, P. (1997). Le remords de l'éclectisme, précurseur de la synthèse de la philosophie et de la révolution? Pierre Leroux, Proudhon et Ferrari lecteurs de Jouffroy. Corpus. Revue de Philosophie, 33, pp. 5-31.

Revista La Moda (1938). Ed. Facsimilar. Buenos Aires, Argentina. 